\title{
In Memoriam Pamela Sklar
}

Neuropsychopharmacology (2018) 43, I |9|-| |92; doi:10.1038/
npp.2018.|

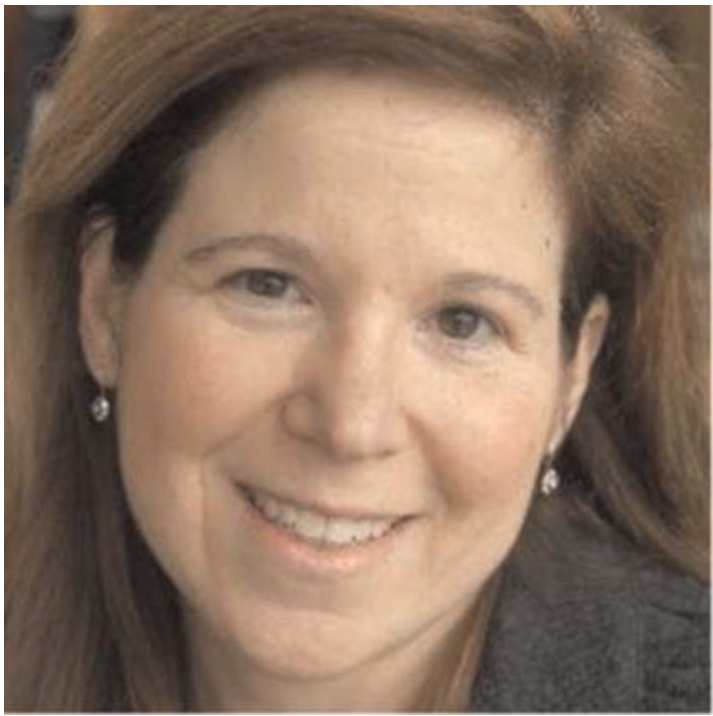

The totality of scientific knowledge is owed to the individuals with each passing generation who ask the right questions, and seek the answers in earnest. One such individual was Pamela Sklar, $\mathrm{MD}, \mathrm{PhD}$ - geneticist, neuroscientist, and clinical psychiatrist-who died on 20 November 2017 at the age of 58. Pamela was a seminal figure in the 'Team Science' revolution that changed the culture of psychiatric research in the 21st century, and her work forms the foundation of our current understanding of the neurobiology of mental illness. A scientific pioneer, a trailblazer for women in science, and an exemplar of bravery in the face of adversity, Pamela will be remembered as among the most influential figures in modern psychiatry.

Innovator, mother, leader, wife, musician, sister, doctor, daughter, athlete, friend-'She was proof that you can have it all,' said Ariella Cohain, $\mathrm{PhD}$, a postdoctoral researcher who worked with Pamela. Born and raised in the Baltimore area of Maryland, Pamela attended St John's College in Annapolis where in 1981 she earned a BA in Classics/Philosophy. She next trained at Johns Hopkins, earning an MD in 1985 and a $\mathrm{PhD}$ in Neuroscience in the laboratory of Solomon Snyder in 1988. At Columbia College of Physicians and Surgeons, she completed a psychiatry residency while doing postdoctoral research in the laboratory of Richard Axel, before joining the faculty as Assistant Professor in 1993. She moved to Boston in 1997 and over the course of a decade built a psychiatric genetics research group that grew into an academic powerhouse at the Broad Institute.

In 2011, she moved to Mount Sinai in New York City, initially as the founding Chief of the Division of Psychiatric Genomics and later as Chair of the Department of Genetics and Genomic Sciences, a position she held at the time of her death. She was a Fellow of the American College of Neuropsychopharmacology (2010) and the National Academy of Medicine (2013). Her awards include the Colvin Prize from the Brain and Behavior Research Foundation (2016), and the Lifetime Achievement Award from the International Society of Psychiatric Genetics (2017).

These accolades do not do justice to her brilliant career. With advances in genetics in the 1980s, it came to be assumed that the origins of mental illness would be explained by individual genes. However, when Pamela entered the field two decades later, this had not occurred. 'There were lots of publications, they were very high profile,' she reflected in October of 2016. 'They were all wrong.' She hypothesized that mental illness is polygenic, meaning not just one or even a few but rather hundreds of genes contribute to disease risk. To test this hypothesis would require a study population of a scale with no precedent in the history of psychiatry. 'Back then, Pamela was visionary,' recalls colleague Patrick Sullivan, MD. 'She realized we'd need many thousands of cases, far more than any group could get on their own.'

The odds of bringing such studies to bear were stacked against Pamela. In his eulogy, colleague Eric Nestler, MD, $\mathrm{PhD}$ recalled how she had little support from either psychiatry or genetics. The latter viewed mental illness as too complicated for rigorous analysis, while the former remained entranced by single-gene hypotheses. Furthermore, biomedical research suffered from a deeply engrained culture of competition where there was no incentive for groups studying the same problem to collaborate. On top of all this, Pamela ran up against the multilayered discriminatory practices encountered by women scientists at every level.

Somehow, she got it done. In part, it was through her extraordinary force of personality. She compelled competing researchers from around the globe to collaborate deeply. Radical at the time, this culture of Team Science has since become the gold standard. Her success was also in part due to her unmatched command of all of the aspects of the science, from clinical phenomena to statistical modeling. As she had hypothesized, these studies established the polygenic nature of mental illness beyond doubt. The field of psychiatry was unaccepting of the complex neurobiology suggested by these findings. 'A Pearl Harbor of schizophrenia research,' declared The New York Times referring to the absence of a simple, single-gene solution when Pamela's team first reported their discovery in Nature in 2009. Pamela was unmoved. 'If this is the genetic architecture, we better deal with it,' she reasoned. 'If many aspects of our DNA are involved, it may mean there is less destiny from any one particular change, and more hope.'

In the course of her pioneering work, Pamela was a steadfast advocate for women in science. Lynn Hendrickson, MBA, worked with Pamela for over a decade. In 2005, when Lynn had recently joined Pamela's team in Boston, the two of them spent weeks preparing a presentation for institutional 
leadership describing a vision for the future of psychiatric research. During the presentation, Lynn sat in one of the side chairs of the board room. The presentation went off without a hitch, but afterwards Lynn recalls Pamela fuming. 'You should always sit AT the table,' she said. It was just one example of how for decades Pamela challenged female colleagues to 'lean in' alongside her, and pursue their dreams boldly.

Pamela's bravery is the stuff of legend. 'The most courageous colleague I have ever met,' said my father, Dennis Charney, MD, an expert on resilience and himself a trauma victim. In the summer of 2016, she was hit by an 18-wheeler while riding her bike on vacation. She was helicoptered to the hospital and found to have broken her scapula among other serious injuries. Back in the lab only a few days later, the wounds on her face still yet to scab, she described her injuries as 'nothing.' She battled cancer for over a decade, twice beating it into remission. After her second bout, she became a competitive triathlete. During her third and last bout, she presided over the most ambitious projects of her career. 'An important challenge is to keep up the momentum,' she said. 'It requires a continued fortitude to really just forge ahead.'

Facing mortality, the final act of Pamela's career was spent preparing the next generation for the road ahead. Just 5 months before she died, she called me into her office to meet about a 'juicy project' she was starting. The DNA of 50000 individuals was to be sequenced, and she wanted a few of us young investigators on her team to push it forward. That day, she gave me a crash course in conducting an endeavor of this scale. In large part, she said, success was dependent upon keeping the trains running on time. Ultimately, though, it would hinge upon recognizing when to let a train run off its rails, such that it might be rebuilt into a train that flies, or a train that glides across water-whatever the moment demands. Our first meeting had been 6 years earlier. Pamela had just joined Mount Sinai, I was a medical student interested in psychiatry. To me, she was larger than life. 'How do I become you?' I asked her. Through a PhD and residency, she mentored by example. This was to be one of our final meetings. Still larger than life, she concluded by laying down the ultimate challenge. 'If I'm not around anymore,' she said, 'this is your chance.' Over the ensuing months, I slowly came to accept that Pamela was never coming back, and those parting words were her way of letting the train run off its rails. Now a new train, built in loving memory of a fearless leader, forges full steam ahead.

\section{ACKNOWLEDGMENTS}

Patrick Sullivan, MD and Eric J Nestler, MD, PhD contributed invaluable feedback on early versions of this article.

$$
\begin{array}{r}
\text { Alexander W Charney }{ }^{*, 1,2} \\
{ }^{1} \text { Department of Psychiatry, Icahn School of Medicine at } \\
\text { Mount Sinai, New York, NY, USA; } \\
{ }^{2} \text { Department of Neuroscience, Icahn School of Medicine at } \\
\text { Mount Sinai, New York, NY, USA } \\
\text { E-mail: alexander.charney@icahn.mssm.edu }
\end{array}
$$

